\title{
SECTIONAL ANATOMY OF THE PETROUS BONE FOR THE STUDY OF THE EAR
}

\author{
Irungbam Deven Singh ${ }^{* 1}$, Ch. Rajlakshmi ${ }^{2}$.
}

${ }^{* 1,2}$ Associate Professor, Department of Anatomy, Regional Institute of Medical Sciences, Imphal, Manipur, India.

\section{ABSTRACT}

\begin{abstract}
Introduction: The temporal bone lies on the lateral side of the skull. It houses most parts of the ear. The petrous is a wedge-shaped part of temporal bone that houses the ear. The ear is the organ of hearing and balance. It has three parts-external, middle and internal. Sectional anatomy allows the study of the relation between anatomic structures.

Materials and Methods: Seven left petrous bones separated from cadaveric temporal bones were used for the study. About $2 \mathrm{~mm}$ thick sections were cut in three axes-longitudinal, transverse and horizontal. They were studied with the naked eye or by using a hand lens.

Results: In the longitudinal sections, the earlier sections showed internal acoustic meatus. Later sections show cochlea, vestibule and middle ear structures and the external acoustic meatus. In the transverse sections, earlier sections showed structures related to anterior wall of middle ear. Near the middle, cochlea could be visualized. Further posterior sections showed middle ear, vestibule and semicircular canal. Then, the mastoid antrum and air cells were seen. In the horizontal sections, the middle ear and mastoid antrum were opened from above. Lower sections showed middle ear structures, vestibule, semicircular canals and cochlea were seen.

Conclusion: Structure of the ear is complex. Students find it difficult to understand because of the miniature component structures and also their deep location inside the petrous. Sectional anatomy not only shows the relations between structures but also a vivid picture of many of these structures.
\end{abstract}

KEY WORDS: Ear, Temporal bone, Petrous, Sectional anatomy.

Address for Correspondence: Dr. Irungbam Deven Singh, Associate Professor, Department of Anatomy, Regional Institute of Medical Sciences, Imphal, Manipur, India.

E-Mail : irungdesi@gmail.com.

\section{Access this Article online}

\section{Quick Response code}

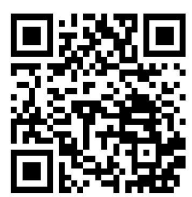

DOI: $10.16965 /$ ijar.2017.430

Web site: International Journal of Anatomy and Research

ISSN 2321-4287

www.ijmhr.org/ijar.htm

Received: 21 Aug 2017

Peer Review: 28 Aug 2017

Revised: None
Accepted: 20 Oct 2017

Published (O): 01 Dec 2017

Published (P): 01 Dec 2017

\section{INTRODUCTION}

The ear is the organ of hearing and balance. It has three parts-external, middle and internal. The external ear consists of pinna and a passage called external auditory meatus (EAM) that leads to the middle ear. The EAM enters the petrous obliquely. The middle ear is a narrow space which contains many important structures including the three ossicles and two small muscles. The sound collected by the external ear is conducted by the ossicles to the internal ear which consists of bony and membranous labyrinths. The structure of the labyrinth is complex and consists of vestibule and 3 semicircular canals. The 3 semicircular canals (SCs) namely, superior (SSC) (or anterior), posterior (PSC) and lateral (LSC) contain the semicircular ducts whereas the vestibule houses the utricle and saccule.

The temporal bone lies on the lateral side of 
the skull. It houses the most parts of the ear. The petrous is a wedge-shaped part of temporal bone placed obliquely with its axis making an angle of $45^{\circ}$ with the transverse axis [1]. It has an apex, a base and three surfaces. The surfaces are anterior which faces anteriorly, upwards and slightly laterally; posterior which faces posteriorly and medially and inferior which faces downwards. The opening of the internal acoustic meatus (IAM) lies in the posterior surface near its middle. It is directed laterally and slightly downwards. The carotid canal enters inferior surface of the petrous anteromedial to the jugular fossa and then runs forwards and medially to emerge at the apex. The external acoustic meatus lies between tympanic and squamous parts and is directed medially almost in line with IAM. The anterior surface presents the arcuate eminence which is regarded to be produced by the underlying SSC.

The ear is a difficult area for routine anatomical studies. The ear structures are at the microscopic scale and often necessitate microscopeaided dissections or examinations. Moreover, most part of the ear is housed inside the petrous part of the temporal bone which is regarded as the hardest bone ${ }^{2}$ and so it requires decalcification before embarking onto dissections or histological processing and examination. Special equipments are required for sectioning of the bone when decalcification is not undertaken but these are not easily available.

Sectional anatomy allows the study of the relation between anatomic structures. This approach is a slight deviation from the routine anatomical dissections but it definitely has its application because the usual gross dissection of the middle ear cannot provide all the information necessary for understanding the ear anatomy. Though it cannot replace usual gross dissections or histological studies, it may be undertaken as a part of the routine gross dissection.

A longitudinal section will give information about superior/inferior and medial/lateral relations; transverse section will give information about the superior/inferior and medial/lateral relations and a horizontal section will give information about the medial/lateral and anterior/posterior relations between structures. The various pieces of information gathered from these sections can be used to sort of reconstruct a mental 3D picture.

\section{MATERIALS AND METHODS}

Seven left petrous bones separated from cadaveric temporal bones of the Department of Anatomy, Regional Institute of Medical Sciences, Imphal were used for the study. A handsaw with a thin blade was used to cut the sections manually. Serial sections about $2 \mathrm{~mm}$ thick were cut in the longitudinal (parallel to the posterior surface of the petrous proceeding from medial to lateral), transverse (perpendicular to the posterior surface of the petrous proceeding from apex to base) and horizontal (parallel to the anterior surface of petrous proceeding from superficial to deep) planes. The tissue debris in the sections were carefully washed using a disposable syringe and needle. The sections were studied with the naked eye or with the help of a magnifying lens. For the sake of simplicity, the faces of the sections are termed medial (instead of posteromedial) and lateral (instead of anterolateral) for the longitudinal sections, anterior (instead of anteromedial) and posterior (instead of posterolateral) for the transverse sections and upper (instead of anterosuperolateral) and lower (instead of posteroinferomedial) for the horizontal sections.

\section{RESULTS}

\section{Longitudinal Sections}

The structures seen in longitudinal sections are shown in Figs.1.1 to 1.5.

Fig.1.1: Longitudinal Section 1 (left petrous; medial face).

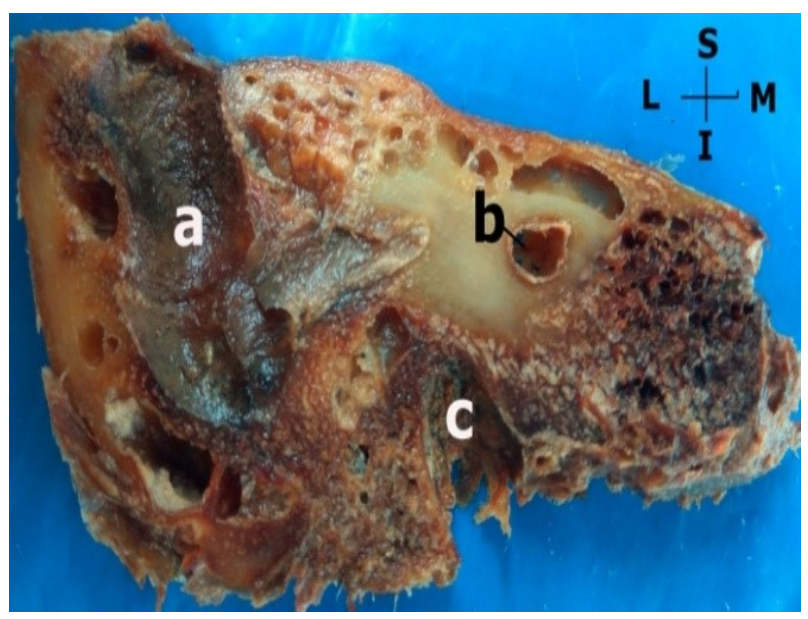

$a=$ sigmoid sulcus, $b=$ internal acoustic meatus, $c=j u g u l a r$ fossa, $\mathrm{S}=$ superior, I=inferior, $\mathrm{M}=$ medial $\& \mathrm{~L}=$ lateral. 
Fig.1.2: Lateral face of Longitudinal Section 1.

$$
{ }_{\mathrm{M}}^{\mathrm{S}} \mathrm{L}
$$

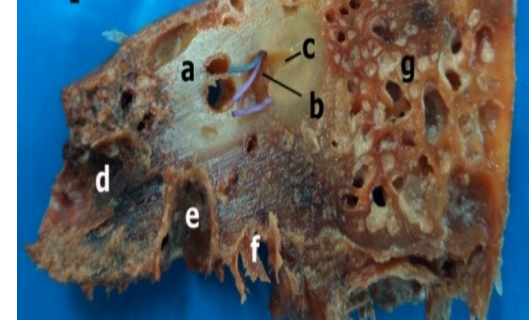

$a=$ internal accoustic meatus, $b=$ vestibule, $c=$ lateral semicircular canal, d\&e=carotid canal, f=jugular fossa, $\mathrm{g}=$ mastoid cells $\mathrm{S}=$ superior, I=inferior, $\mathrm{M}=$ medial \& $\mathrm{L}=$ lateral.

Fig.1.3: Longitudinal Section 2 (left petrous; medial face).

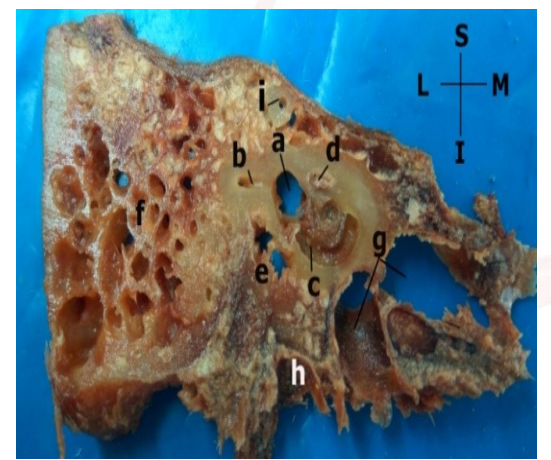

$a=$ vestibule, $b=$ lateral semicircular canal, $c=$ cochlear canal, $d=$ facial nerve in its canal, e=middle ear cavity, $\mathrm{f}=$ mastoid air cells, $\mathrm{g}=$ carotid canal, $\mathrm{h}=$ jugular fossa, $\mathrm{i}=$ superior semicircular canal, $\mathrm{S}=$ superior, I=inferior, $\mathrm{M}=$ medial $\& \mathrm{~L}=$ lateral.

Fig.1.4: Longitudinal Section 3 (left petrous; medial face).

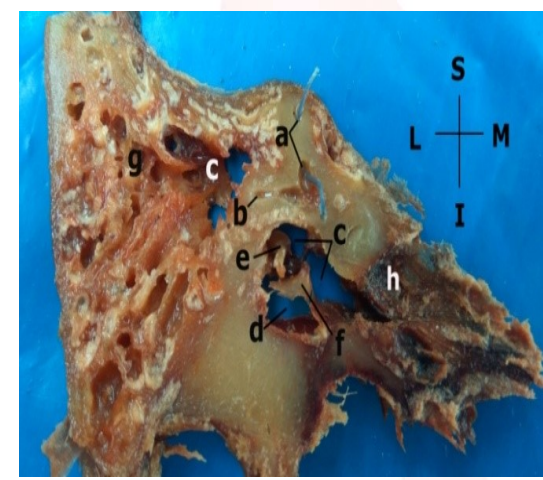

$a=$ superior semicircular canal with probe, $b=$ lateral semicircular canal, $c=$ middle ear cavity, $d=$ external acoustic meatus, e=incus, f=tympanic membrane, $\mathrm{g}=$ mastoid air cells $\& \mathrm{~h}=$ carotid canal, $\mathrm{S}=$ superior, I=inferior, $\mathrm{M}=$ medial \& L=lateral.

Fig.1.5: Longitudinal Section 4 (left petrous; medial face).

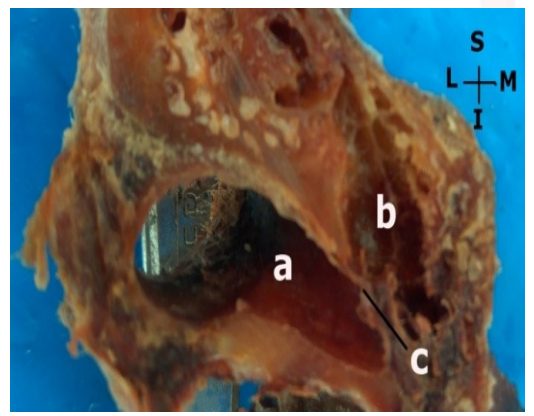

$a=$ external acoustic meatus, $b=$ middle ear cavity, c=tympanic membrane, $\mathrm{S}=$ superior, $\mathrm{I}=$ inferior, $\mathrm{M}=$ medial \& L=lateral.

\section{Transverse Sections}

The structures seen in transverse sections are shown in Figs.2.1 to 2.9.

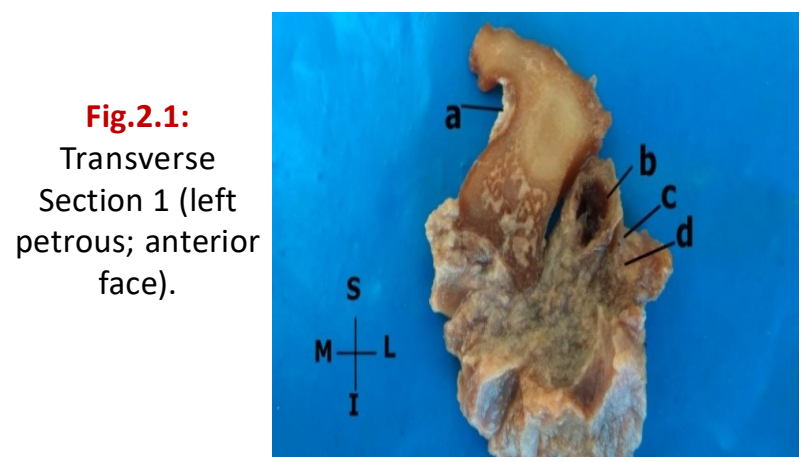

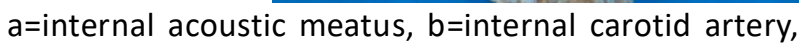
$\mathrm{c}=$ tensor tympani, $\mathrm{d}=$ =auditory tube, $\mathrm{S}=$ superior, $\mathrm{I}=$ inferior, $\mathrm{M}=$ medial $\& \mathrm{~L}=$ lateral.

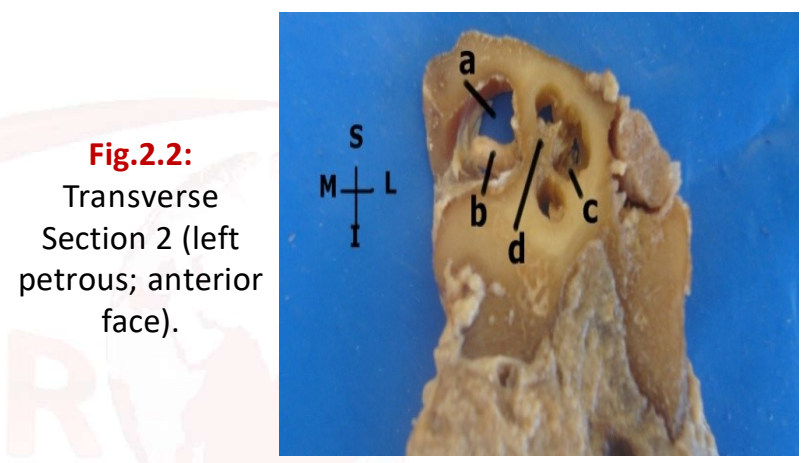

$a=$ fundus of internal acoustic meatus, $b=$ cochlear nerve, $\mathrm{c}=$ cochlea, $\mathrm{d}=$ =modiolus, $\mathrm{S}=$ superior, $\mathrm{I}=$ inferior, $\mathrm{M}=$ medial \& L=lateral.

Fig.2.3:

Transverse Section 3 (left petrous; anterior face).

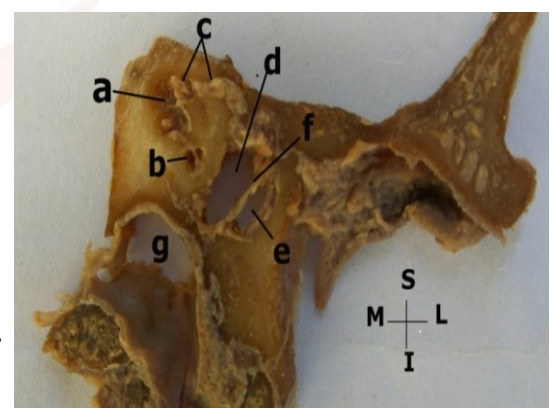

$a=$ fundus of internal acoustic meatus, $b=$ basal turn of cochlear canal, c=facial nerve, $d=$ middle ear, e=external acoustic meatus, $f=$ tympanic membrane, $g=b u l b$ of internal jugular vein, $\mathrm{S}=$ superior, I=inferior, $\mathrm{M}=$ =medial \& L=lateral.

\section{Fig.2.4:}

Transverse Section 4 (left petrous; anterior face).

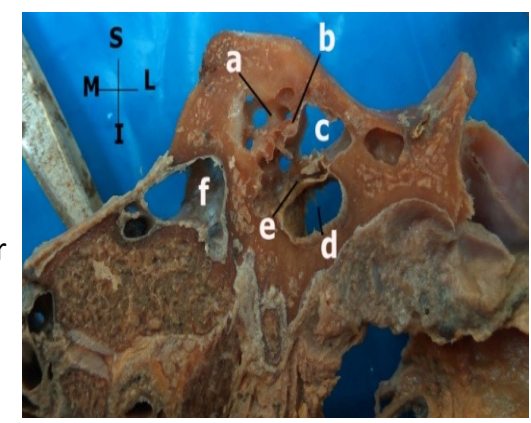

a=vestibule with the 5 openings of semicircular canals, $b=$ facial canal, $c=$ mastoid antrum, $d=$ external acoustic meatus, e=tympanic membrane $\& f=b u l b$ of internal jugular vein, $\mathrm{S}=$ superior, $\mathrm{I}=$ inferior, $\mathrm{M}=$ medial $\& \mathrm{~L}=$ lateral. 


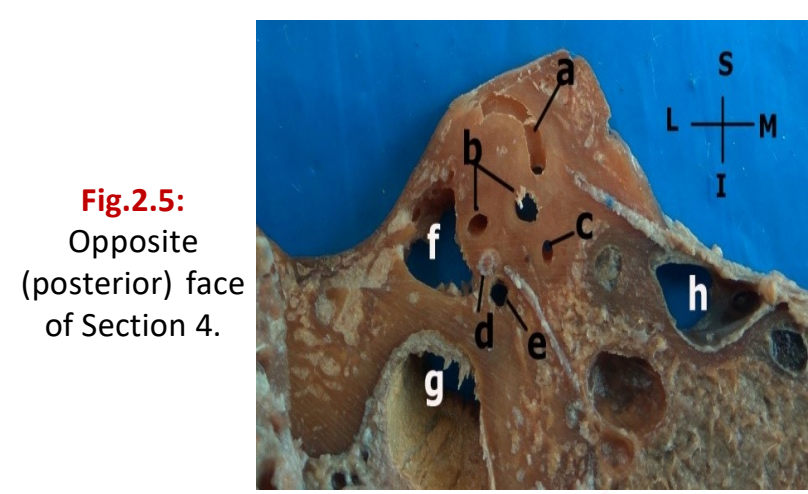

$a=$ superior semicircular canal, $b=$ lateral semicircular canal, $c=$ posterior semicircular canal, $d=$ facial nerve in facial canal, $\mathrm{e}=$ middle ear, $\mathrm{f}=$ aditus to mastoid antrum, $\mathrm{g}=$ external acoustic meatus, $\mathrm{h}=$ sigmoid sinus, $\mathrm{S}=$ superior, I=inferior, $M=$ medial \& $\mathrm{L}=$ lateral.

Fig.2.6:

Transverse

Section 5 (left petrous; anterior face).

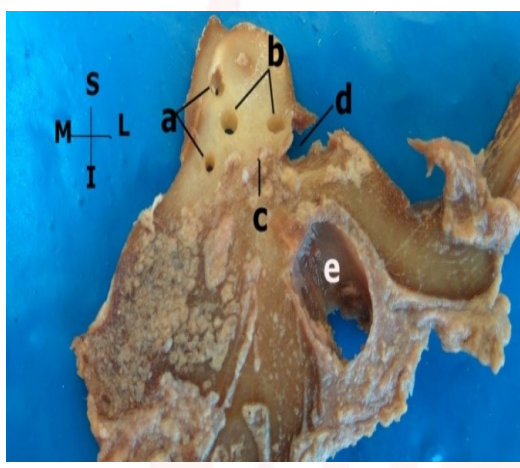

$a=$ superior semicircular canal, $b=$ lateral semicircular canal, $c=$ facial nerve in facial canal, $d=$ mastoid antrum, e=external acoustic meatus, $\mathrm{S}=$ superior, I=inferior, $\mathrm{M}=$ medial \& $\mathrm{L}=$ lateral.

Fig.2.7: Transverse section 7 (left petrous; anterior face).

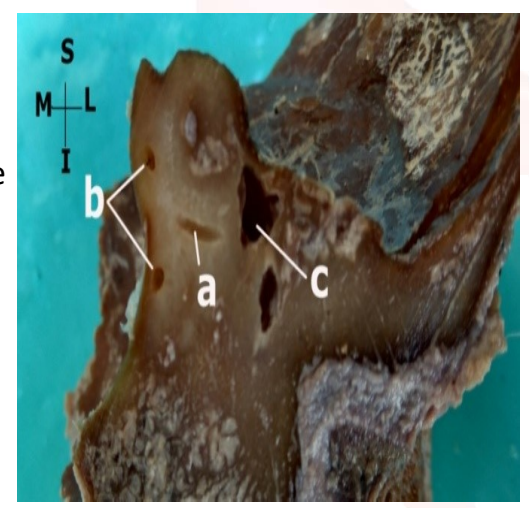

$a=$ lateral semicircular canal, $b=$ posterior semicircular canal, $\mathrm{S}=$ superior, $\mathrm{I}=$ inferior, $\mathrm{M}=$ medial $\& \mathrm{~L}=$ lateral.

Fig.2.8: Transverse

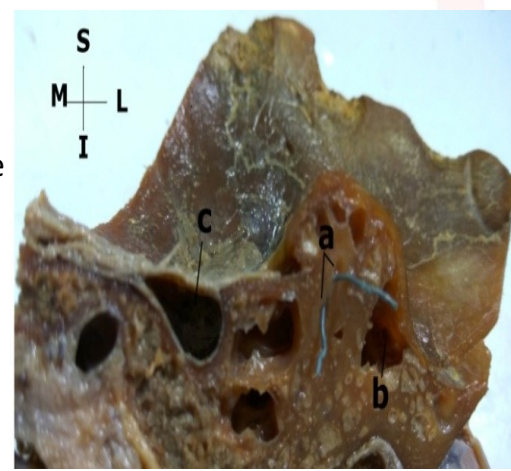

$a=$ posterior semicircular canal with probe, $b=$ mastoid antrum, c=sigmoid sinus, $\mathrm{S}=$ superior, $\mathrm{I}=\mathrm{inferior}$, $M=$ medial \& $L=$ lateral.
Fig.2.9:

Transverse

Section 8 (left petrous; anterior face).

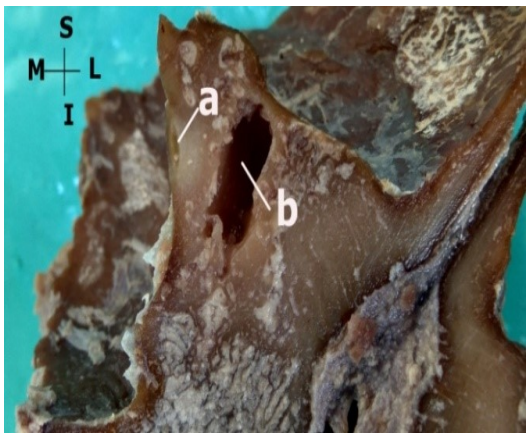

$a=$ posterior semicircular canal, b=mastoid antrum, $\mathrm{S}=$ superior, I=inferior, $\mathrm{M}=$ medial $\& \mathrm{~L}=$ lateral.

\section{Horizontal Sections}

The various horizontal sections are shown in Figs.3.1 to 3.5.

Fig.3.1:

Horizontal Section 1. (left petrous, lower face).

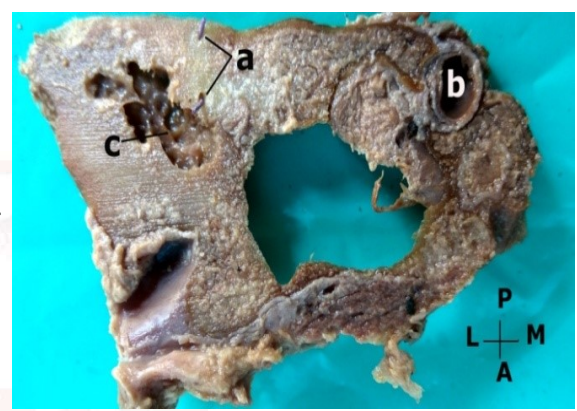

$a=$ superior semicircular canal, $b=$ internal carotid artery \& $\mathrm{c}=$ middle ear and mastoid antrum and their roof, $\mathrm{A}=$ anterior, $\mathrm{P}=$ posterior, $\mathrm{M}=$ medial $\& \mathrm{~L}=$ lateral.

Fig.3.2: Horizontal Section 2 (left petrous, upper face).

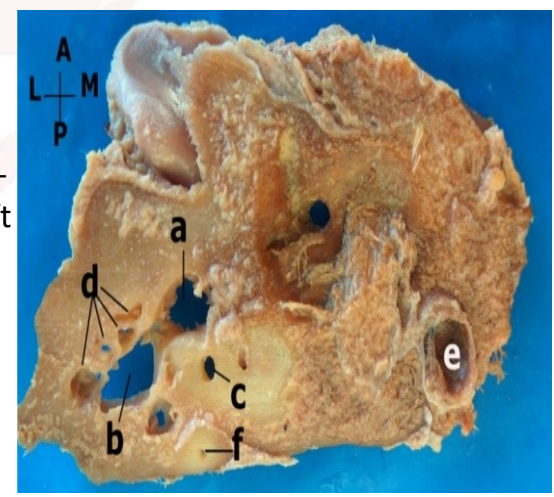

$\mathrm{a}=$ middle ear, $\mathrm{b}=$ mastoid antrum, $\mathrm{c}=$ vestibule (upper part) \& d=mastoid air cells, e=internal carotid artery, $\mathrm{f}=$ superior semicircular canal, $\mathrm{A}=$ anterior, $\mathrm{P}=$ posterior, $\mathrm{M}=$ medial \& $\mathrm{L}=$ lateral.

Fig.3.3: Lower surface of Section 2.

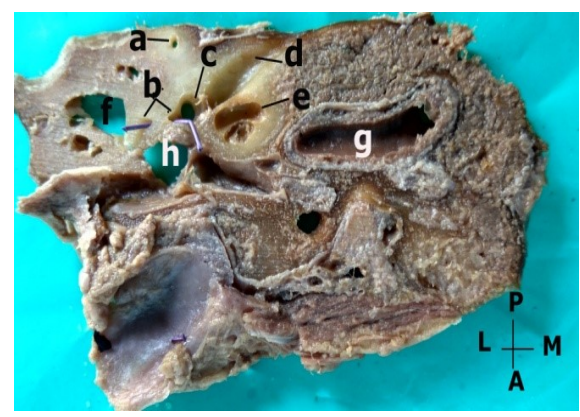

$a=$ superior semicircular canal, $b=$ lateral semicircular canal, c=vestibule, $d=i n t e r n a l$ acoustic meatus, $\mathrm{e}=$ cochlea, $\mathrm{f}=$ mastoid antrum, $\mathrm{g}=$ internal carotid artery, $\mathrm{h}=$ middle ear, $\mathrm{A}=$ anterior, $\mathrm{P}=$ posterior, $\mathrm{M}=$ medial \& $\mathrm{L}=$ lateral. 


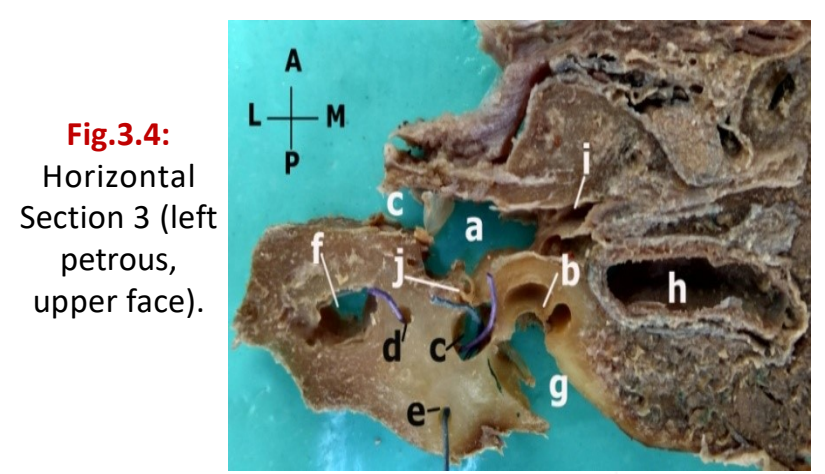

$\mathrm{a}=$ middle ear, $\mathrm{c}=$ external auditory meatus, $\mathrm{b}=$ cochlea, $c=$ vestibule, $d=$ lateral semicircular canal, e=superior semicircular canal, $f=$ mastoid antrum, $g=i n t e r n a l$ auditory meatus, $\mathrm{h}=$ internal carotid artery, $\mathrm{i}=$ auditory tube, $\mathrm{j}=$ stapes in oval foramen, $\mathrm{A}=$ anterior, $\mathrm{P}=$ posterior, $\mathrm{M}=$ medial $\& \mathrm{~L}=$ lateral.

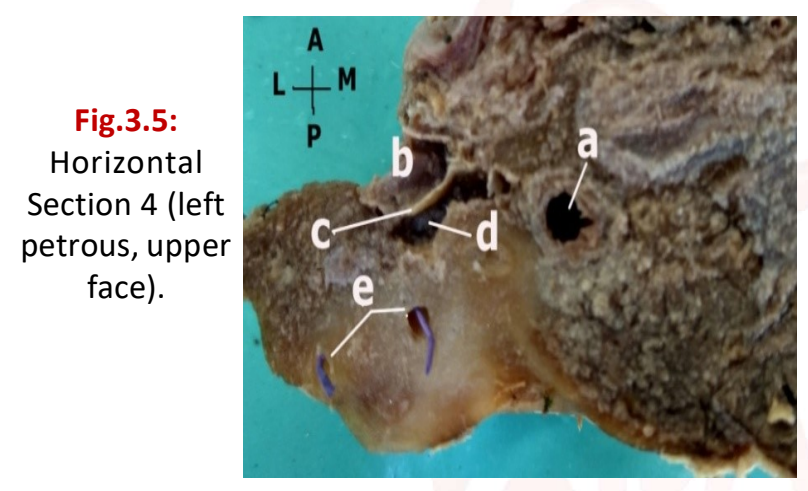

$a=$ internal carotid artery, $b=$ external acoustic meatus, $c=$ tympanic membrane, $d=$ middle ear (floor), e=posterior semicircular canal with probe, $\mathrm{A}=$ anterior, $\mathrm{P}=$ posterior, $\mathrm{M}=$ medial \& $\mathrm{L}=$ lateral.

\section{DISCUSSION}

Longitudinal Sections: The longitudinal sections gave a triangular surface with its apex toward the apex of the petrous and base toward the mastoid part of the temporal bone.

Section 1 (Fig.1.1) showed very few structures of the ear except the internal acoustic meatus which was found closer to the apex than the base of petrous; the sigmoid sulcus descended in the posterior part of the petrous becoming gradually smaller. The jugular fossa was seen below and behind the IAM. The carotid canal was not seen at this plane as it lies more anteriorly.

The opposite face of the first slice (Fig.1.2) showed the fundus area of the internal acoustic meatus. The section had been done right at the fundus area as the transverse crest of the fundus was visible from this aspect. Behind the internal acoustic meatus was the vestibule into which the posterior end of the LSC was seen to enter. The PSC has been imprisoned in the thickness of this section and its presence can be confirmed with a flexible probe (Fig.1.2, violet probe) introduced from the vestibular cavity. In the same section, the SSC had been cut cross-wise and this end could be seen a short distance from the vestibule (Fig.1.2, blue probe). The two ends of the SSC and PSC, after uniting to form the crus commune, open into the vestibule. The arcuate eminence is considered an eminence on the superior surface raised by the SSC [2-4]. But many studies have found it to be not directly over the SSC [5-8]. In the present study the SSC was found to lie rather anterior to the arcuate eminence.

In Section 2 (Fig.1.3), the basal coil of the cochlea joined the vestibule from the lower limit of its base. The other end of this part of the cochlear canal turned laterally and its continuation can be noted by passing a probe. From this, it can be inferred that the cochlea is placed inside the petrous in such a manner that its axis lies perpendicular to the axis of the petrous and apical turns are more lateral than the basal turns. The vestibule was well visualized and the posterior end of the LSC was seen entering it (Fig.1.3b). The LSC was cut such that near the vestibule it was shallower because from here the LSC will turn backwards and laterally. A single cross-section of the SSC (Fig.1.3i) was seen well above the vestibule which was directed laterally and from here it will turn laterally and downwards. But the plane of the section had passed lateral to the PSC. The facial nerve ran in its canal above and in between cochlea and vestibule (Fig.1.3d). Here, the nerve lies anterosuperior to the vestibule [9].

In the next section (Fig.1.4), the middle ear cavity was well seen. The section passed obliquely through the lower part of tympanic membrane and thereby opening up the external acoustic meatus. The lower parts of incus and malleus were seen with the umbo of the tympanic membrane. The bend of the carotid canal (Fig.1.4h) could be seen as a very shallow groove near the apex of the petrous. But the jugular fossa was no more seen as the section had passed anterior to it. The anterior ends of the LSC and SSC are seen as two grooves converging into the vestibule. A little above this, the cross-section for the SSC was seen and from 
here the SSC will turn medially and the continuity of this opening with the vestibule can be confirmed by introducing a probe (Fig.1.4a). The mastoid antrum with its air cells was seen posteriorly but its continuity with the middle ear was not seen in this plane of section.

In the next section (Fig.1.5), the most prominent structure was the EAM which gave an elliptical profile as it had been cut obliquely. Above the anterior part of the external acoustic meatus, the lateral wall of the middle ear could be seen being separated from the former by a part of the tympanic membrane.

Transverse Sections: Transverse sections gave a triangular outline. The internal acoustic meatus showed a curve margin which opened on the posterior surface of the petrous (left side of the figure) (Fig.2.1a). This is because the IAM begins as a groove on the posterior surface of the petrous. The IAM opens approximately in the centre of the posterior surface. In these sections, this foramen will become more and more separated from the posterior surface until the fundus is reached as evident from the oblique direction of the meatus. In Section 1 (Fig.2.1), the internal carotid artery was seen as it turned forwards in the carotid canal (Fig.2.1b). From here, the carotid canal took a horizontal course to emerge at the apex of the petrous bone and then it entered the posterior wall of the foramen lacerum. The vertical course of the internal carotid artery here was related to the anterior wall of the middle ear.

A longitudinal section of cochlea (Fig.2.2c) showed 5 cross-sections of the cochlear canal. The cochlear section showed a broader basal end lying close to the fundus and facing medially (left side of the figure) and a narrower apical end directed laterally (right side of the figure). The cross-sections of the cochlear canal were not placed at the same level with regard to the axis of the cochlea which is indicative of the spiral course of the canal and the size of the canal gradually decreased toward the apex. In the same section, the osseous spiral lamina could be seen in the modiolar side of the wall of the cochlear canal running along its axis of the cochlear canal. The cochlear nerve entered the base of the cochlea (Fig.2.2b) which it does from the anteroinferior part of the fundus of the internal auditory meatus. The nerve fascicles are arranged in a spiral fashion and perforate the area which is known as the tractus spiralis foraminosus.

A section near the fundus (Fig.2.3) showed the nerves passing through the different areas of the fundus but the cochlea was no more seen except its connection with the vestibule. The facial nerve was seen as it traversed the initial part (labyrinthine segment) of its canal. A more posterior section (Fig. 2.4) showed the vestibule, middle ear and external auditory meatus. The middle ear space seemed larger than that of external auditory meatus. This is because the axis of the latter is oblique to that of the petrous and the section passed through the anterior narrow end of the external auditory meatus. The tympanic membrane was seen separating these two spaces. Many of the middle ear structures could be seen including the stapes which was attached to the ovale window.

The vestibule received the 5 openings of the 3 SCs (Fig.2.4). The SCs enter on the posterosuperior aspect of the vestibule [2,9]. The SSC lies transverse to the axis of the petrous, the PSC parallel to the posterior surface of the petrous whereas the LSC is aligned horizontally running backwards and laterally [2]. How these SCs appear in sections depend on two things viz. their orientation and the plane of section. The posterior end of the LSC opened in between the crus commune and inferior end of the PSC. The posterior end of LSC opened closer to the crus commune than to the opening of its lower end of the PSC (Fig.2.4). The cross-section of facial nerve in its tympanic part of the canal (Fig.2.4b) was seen in the medial wall of the middle ear just below the section of the LSC. This relation between the LSC and facial canal can be regarded as very classic. In a more posterior section, the facial canal was found to be directed downwards and backwards which could be confirmed by using a probe. This is so because the facial canal turned inferiorly into the posterior wall of the middle ear leaving the LSC. The SSC is usually aligned perpendicular to the axis of the petrous. A section which is perpendicular to the axis of petrous may give a longitudinal section of the SSC (Fig.2.5a).

Typically, the PSC curves backwards parallel to 
the axis of the petrous in the vertical plane. A transverse section behind the vestibule showed 2 cross-sections of each of PSC and LSC (Fig.2.6). As the plane of section moved further posteriorly, the two cross-sections of the PSC approximated each other and this could be confirmed by passing a flexible probe (Fig.2.8). When the section passed through its posterior-most convexity, the two cross-sections fused and was represented by a curve horizontal groove (Fig.2.7). Like the PSC, in a section just behind the vestibule, the LSC showed two cross-sections. They approached each other as the plane of section went further posteriorly and later, as in the case of PSC, the two cross-sections fused and was marked by a vertical groove (Fig.2.9).

When the four cross-sections of the SSC and PSC were seen together-those of the PSC aligned vertically and those of LSC horizontally and the medial cross-section of the LSC was found in between but a little lateral to those of the PSC (Fig.2.6). The PSC extended more posteriorly than the LSC and therefore, the cross-sections of the LSC were closer to each other than those of the PSC and when the LSC ended after the fusion of its 2 cross-sections, the openings of the PSC were still separate (Fig.2.8).

Horizontal Sections: The lower face of the first section (Fig.3.1) showed the two cross-sections of the SSC (Fig.3.1a) aligned perpendicular to the axis of the petrous. The middle ear and the mastoid antrum (Fig.3.1c) were seen as continuous cavity with their roof which is formed by the tegmen tympani. The IAM was seen at the apex of the petrous (Fig.3.1b). No other SC was seen. In the next secton (Fig.3.2), the middle ear and mastoid antrum were seen. They seemed to be separated but were actually continuous at the aditus of the matoid antrum. Mastoid air cells were seen as small cavities adjacent to the mastoid antrum. The medial end (Fig.3.2f) of the SSC was seen close to the medial margin but its lateral end couldn't be seen because the section passed obliquely through the upper part of vestibule (Fig.3.2c). The round profile (suggestive of a transverse section) of the internal carotid artery was seen at the apex of the petrous.

The lower face of Section 2 (Fig.3.3) showed many ear structures. The IAM (Fig.3.3d) passed obliquely to end in the fundus where it was capped by cochlea and vestibule. The SSC produced a cross-section near the posterior limit (upper margin of the diagram). The ICA (Fig.3.3g) gave a elongated outline as it was cut longitudinally in its horizontal part. A peripheral longitudinal section of the cochlea (that doesn't pass through the modiolus) gave a few elongated transverse profiles of the cochlear canal, the apical section was the shortest and the longest, basal (Fig.3.3e).

In the lower section (Fig.3.4), the cochlea and vestibule were found closely applied to the fundus of the internal auditory meatus. The mastoid antrum appeared to have moved more posteriorly. Many of the middle ear structures were not seen at such level (probably partly because of dislodgement during sectioning) except the stapes which was usually found attached to the ovale window after being dislocated from incus. As the plane of section (which faced upwards, laterally and forwards) was oblique to the plane of the LSC, only one cross-section could be seen (Fig.3.4d). But its connection with the vestibule could be confirmed by inserting a probe (Fig.3.4, violet probe). Similarly, the SSC showed only one cross-section near the posterior surface of petrous and from here it will turn downwards and meet the upper end of the PSC before it opens into the vestibule (Fig.3.4, blue probe). The lateral end of the SSC and anterior end of the LSC were not seen in this plane because the section passed below their openings into the vestibule. The internal carotid artery was cut longitudinally along its horizontal course in the petrous.

The fourth section (Fig.3.5) showed the vertical part of internal carotid artery cut transversely giving a round profile. It seemed to have shifted near the middle ear as it came to be related to its anterior wall. The two openings of the PSC only were seen (Fig.3.5, probe) as it was the lowest SC.

\section{CONCLUSION}

Structure of the ear is complex. Students find it difficult to understand because of the miniature component structures and also their deep location inside the petrous. Sectional anatomy not only shows the relations between structures but 
also a vivid picture of many of them. Therefore, it is indispensable for better understanding of gross anatomy. In the present study, the authors used manual method of sectioning. The limitations of this method were-first, inability to make thinner sections leading to loss of structures or information in the plane of section or in the thickness of the sections and second, difficulty in maintaining a uniform thickness. Moreover, the method employed in the present study may not be ideal for the study of the membranous labyrinth for which histological sections after decalcification will be the better choice. The knowledge of the normal anatomy of the ear is often called for in surgical procedures in this region such as removal of acoustic nerve tumor, repair of canal dehiscence, etc $[10,11]$.

\section{Conflicts of Interests: None}

\section{REFERENCES}

[1]. Mansour S, Magnan J, Hassan H, Nicholas K, Louryan S. Comprehensive and Clinical Anatomy of the Middle Ear. New York : Springer; 2013.

[2]. Standring S. Gray's Anatomy : The Anatomical Basis of Clinical Practice, $40^{\text {th }}$ edition. Edinburgh: Elsevier; 2005, p. 633-50.

[3]. Snell RS. Clinical Anatomy by Systems. Baltimore: Lippincott Williams \& Wilkins; 2007.

[4]. Sinnatamby CS. Last's Anatomy : Regional and Applied. $12^{\text {th }}$ edition. Edinburgh : Elsevier; 2011.

[5]. Tsunoda A, Kimura Y, Sumi T, Komatsuzaki A, Sato T. The arcuate eminence is not a protrusion of the superior semicircular canal but a trace of sulcus on the temporal lobe. J Laryngol Otol. 2000 114(5):339-44.
[6]. Tsunoda A. Arcuate eminence in Caucasian populations. J Laryngol Otol. 2001 115(1):9-13.

[7]. Djalilian HR, Thakkar KH, Hamidi S, Benson AG, Mafee MF. A study of middle cranial fossa anatomy and anatomic variations. Ear Nose Throat J. 2007 86(8):474, 476-81.

[8]. Seo Y, Ito T, Sasaki T. Nakagawara J, Nakamura H. Assessment of the anatomical relationship between the arcuate eminence and superior semicircular canal by computed tomography. Neurol Med Chir (Tokyo) 2007;47(48):335-9. Available at https:// pdfs.semanticscholar.org/6 a $37 /$ 4e1c500cc996e554fc439155ace571afc70f.pdf. Accessed on 21/8/17.

[9]. Romanes GJ. Cunningham's Manual of Practical Anatomy. Vol. 3 (Head and Neck and Brain), 15 th edition. New Delhi: Oxford University Press; 1986.

[10]. Sennaroglu L, Slattery WH III. Petrous anatomy for middle fossa approach. The Laryngoscope 2003;113:332-342.

[11]. Carter MS, Lukabaugh S, Lee DJ. Endoscopic- assisted repair of superior canal dehiscence syndrome. The Laryngoscope 2014;124:1464-1468.

How to cite this article:

Irungbam Deven Singh, Ch. Rajlakshmi. SECTIONAL ANATOMY OF THE PETROUS BONE FOR THE STUDY OF THE EAR. Int J Anat Res 2017;5(4.3):4660-4667. DOI: 10.16965/ijar.2017.430 